\title{
ГРАЖДАНСКОЕ ОБЩЕСТВО В СОВРЕМЕННОМ ИНФОРМАЦИОННОМ ПРОСТРАНСТВЕ
}

\begin{abstract}
Аннотация. В условиях формирования нового информационного пространства возрастает роль организаций гражданского общества и каждого человека в отдельности. Общественные организации становятся важным источником получения сочиальной информации. Автор делает вывод, что создание новых информачионных механизмов вовлечения общественных структур в выработку политических решений способствует снижению социальных противоречий и конфликтов на уровне стран и целых интеграционных объединений, как например, Европейский союз.
\end{abstract}

Ключевые слова: гражданское общество, информачионное пространство, информационное общество, иивилизационное развитие, неправительственные организации, Европейский союз.

Вряд ли кто-либо станет отрицать, что в мире в результате впечатляющих научно-технических достижений за последние полвека произошёл поистине революционный прорыв в информационной сфере. Но как эти достижения могут отразиться на жизни современного общества, изменится ли роль человека, являющегося основным генератором и получателем информации? Как новые информационные технологии отразятся на деятельности гражданского общества?

Отвечая на эти и многие другие вопросы, связанные с появлением новых информационно-коммуникационных технологий, учёные предложили концепцию «информационного общества» - новой ступени в развитии современной цивилизации, которое знаменует начало «постиндустриального общества». Вглядываясь в будущее развития человечества, американский социолог Даниел Белл в своей книге «Грядущее постиндустриальное общество. Образец социального прогнозирования» ${ }^{1}$ связывает будущее общественное развитие с формированием научного знания как самостоятельного элемента производственных сил, основанного на получении новой информации.

Японский социолог и футуролог, также один из авторов концепции информационного общества, Йошита Масуда в своей работе «Информационное общество как постиндустриальное общество»² хотя и рассматривает общественное устройство преимущественно в экономическом контексте, приходит к выводу, что новые технологии должны будут привести к серьёзным положительным социальным изменениям. Он полагает, что «... производство информационного продукта, а не продукта материального будет движущей силой

(C) Канунников Анатолий Алексеевич - доктор политических наук, ведущий научный сотрудник Центра проблем социального развития Европы Отдела социально-политических исследований Института Европы РАН. Aдpec: 125009, Россия, Москва, ул. Моховая, д. 11, стр. 3. E-mail: a-a-kanunnikov@yandex.ru.

DOI: http://dx.doi.org/10.15211/vestnikieran420195560

${ }^{1}$ Bell D. «The Coming of Post-Industrial Society: A Venture in Social Forecasting Reissue». URL: https: knigogid.ru/ books/484415-gryaduschee-postindustrialnoe-obschestvo/toread (дата обращения: 19.07.2019).

${ }_{2}^{2}$ Masuda Y. The Informational Society as Post-Industrial Society. World Future Society. 1981. P. 33. 
образования и развития общества» ${ }^{1}$. Если исходить из того, что гражданское общество по своей природе защищает интересы и ценности отдельно взятого человека, то весьма интересны взгляды Й. Масуда на трансформацию человеческих ценностей в информационном обществе. Например, он видит будущее информационное общество бесклассовым, в котором не будет противоречий и конфликтов. «Это будет общество согласия, с небольшим правительством и государственным аппаратом»², - утверждает исследователь.

Следует отметить, что идея информационного общества была сформулирована в конце 1960-х - начале 1970-х гг., а сам термин «информационное общество» ввёл Ю. Хаяши, профессор Токийского технологического института.

Проблемы развития информационного общества также вызывают большой интерес в России. Серьёзные исследования в этой области представлены работами И.С. Мелюхина, Д.В. Иванова и многих других российских учёных ${ }^{3}$.

Важность этой темы подчёркивается тем обстоятельством, что 22 июля 2000 г. президенты восьми ведущих индустриальных стран мира подписали «Окинавскую хартию Глобального информационного общества». Руководители самых развитых стран мира признали, что «информационно-коммуникационные технологии (ИТ) являются одним из наиболее важ-ных факторов, влияющих на формирование общества XXI в. Их революционное воздействие касается образа жизни людей, их образования и работы, а также взаимодействия правительст-ва и гражданского общества». «Восьмёрка» выразила готовность «... и далее содействовать укреплению партнёрства между развитыми и развивающимися странами, гражданским обществом, включая частные фирмы и НПО, фонды и учебные заведения, а также международные организации» ${ }^{4}$.

Не остались в стороне от обсуждения этой темы и авторитетные международные форумы. Так, в Декларации, принятой участниками Всемирной встречи на высшем уровне по вопросам информационного общества в Женеве, первый раздел начинается такими словами: «Мы, представители народов мира, собравшиеся в Женеве 10-12 декабря 2003 г. для проведения первого этапа Всемирной встречи на высшем уровне по вопросам информационного общества, заявляем о нашем общем стремлении и решимости построить ориентированное на ин-тересы людей, открытое для всех и направленное на развитие информационное общество, в котором каждый мог бы создавать информацию и знания, иметь к ним доступ, пользоваться и обмениваться ими...» 5 .

Поскольку ряд исследователей, включая учёных Института философии РАН, считают, что «термин «информационное общество» полностью применим только к западным обществам» ${ }^{6}$, было бы интересно ознакомиться с процессом становления информационного общества не только в зарубежных странах, но и целых объединениях стран - например, Европейском союзе (ЕС). Интересно проследить какая роль отводится человеку и организациям

\footnotetext{
${ }^{1}$ Ibid. P. 29.

2 Ibid. P. 46

3 Мелюхин И.С. Информационное общество: истоки, проблемы, тенденции развития. М., Издательство МГУ, 1999; Иванов Д.В. Виртуализация общества. СПб., изд. «Петербургское Востоковедение», 2000.

${ }^{4}$ Окинавская хартия Глобального информационного общества URL: http://www.kremlin.ru/supplement/3170 (дата обращения: 19.07.2019).

${ }^{5}$ Организация Объединённых Наций, ЮНЕСКО. Всемирная встреча на высшем уровне по вопросам информационного общества (г. Женева, 2003 г.). Построение информационного общества - глобальная задача в новом тысячелетии: Декларация принципов (Документ WSIS-03/GENEVA/DOC/4-R, 12 декабря 2003 г.).

${ }^{6}$ Федотова В.Г. «Существуют ли международно-признанные определения информационного общества?». URL: https://iphras.ru/page46589323.htm (дата обращения: 19.07.2019).
}

Научно-аналитический вестник ИЕ РАН, 2019, №4 
гражданского общества в условиях формирования нового информационного пространства. Появляются ли признаки тех изменений, о которых говорили учёные-футурологи?

Известно, что в последние годы в странах Европейского союза идёт поиск совершенствования механизмов управления и принятия оптимальных политических решений на различных уровнях, для чего налаживается широкий диалог с институтами гражданского общества. Многие исследователи придерживаются мнения, что в основании включения всех групп гражданского общества в политический процесс лежит получение информации ${ }^{1}$.

Действительно, выработка эффективной политики (good policies) зависит от получения соответствующей технической, социальной и политической информации. Информация дорогостоящий продукт, и в государствах, где не выделяют на её получение необходимые сред-ства, она может быть недостаточной или даже недостоверной. Средства для получения информации с помощью научных исследований, к сожалению, во многих случаях ограничены. Общество, конечно, может получать соответствующую информацию от мощных экономических структур, однако, как показывает практика, она не всегда бывает объективной. В то же время группы организованного гражданского общества, привлекая в свою деятельность учёных и опираясь на широкую сеть своих первичных организаций, могут предоставлять информацию, которая способна уравновесить информацию, получаемую от лоббистских групп.

Как неоднократно отмечалось в работах о гражданском обществе, в обстановке постоянно меняющейся политической и социальной среды и соответственно меняющихся потребностей населения деятельность общественного сектора направлена на улучшение социальных условий жизни людей. Опыт отношений общественных организаций со структурами Европейского союза свидетельствует о том, что гражданское общество ценится в первую очередь за качественную информацию, которую оно может предоставить. В то же время, выступая в качестве партнёров руководящих структур ЕC, организации, предоставляющие информацию, должны быть достаточно компетентны и авторитетны. Например, в одном из документов Евросоюза о гражданском обществе говорится: «НПО обязаны продемонстрировать, что они имеют опыт, систему управления и внутреннего контроля для выполнения соответствующей работы от имени Комиссии» ${ }^{2}$.

Такие требования побудили ряд общественных организаций разработать конкретные политические, технические, социологические и административные параметры, соответствие которым должно свидетельствовать об их компетентности и достоверности информации, которой они обладают. Например, на местном и наднациональном уровнях экологические организации, зачастую имея узкоспециализированную направленность, обладают специфическими знаниями и информацией в таких секторах, как транспорт, сельское хозяйство или энергетика ${ }^{3}$, т.е. информацией, которая особенно ценится на уровне ЕС из-за двух основных факторов. Один из них заключается в том, что персонал чиновников Европейского союза сравнительно немногочисленный и имеет ограниченные средства и полномочия для приобретения нужной информации, чтобы оперативно принимать решения. Второй заключается в том, что идеологическое разнообразие и многочисленность

\footnotetext{
${ }^{1}$ См., например: Walker J. L. Mobilizing Interest Groups in America: Patrons, Professions and Social Movements, Ann Arbor: University of Michigan Press, 1991.

2 European Commission. «The Commission and Non-Governmental Organisations: Building a Stronger Partnership» COM (2000) 11 final, 18 January 2000. P. 1-26.

${ }^{3}$ Rootes C. Environmental Protest in Western Europe, Oxford: Oxford University Press, 2007; Rootes C. Acting Locally: Local Environmental Mobilizations and Campaigns, London: Routledge, 2008.
} Научно-аналитический вестник ИЕ РАН, 2019, №4 
административно-структурных подразделений Европейской комиссии делают собственную научно-техническую экспертизу весьма спорной ${ }^{1}$. Поэтому руководители различных управлений предпочитают пользоваться экспертизой гражданского общества, организаций, которым они могут доверять в силу согласия с их ценностями и политической ориентацией.

Некоторые исследователи считают, что участие гражданского общества в обсуждении тех или иных проблем может способствовать более глубокому изучению политики в конкретной области, что весьма полезно для всего общественного сектора ${ }^{2}$. Этому процессу могут способствовать межорганизационные связи различных ассоциаций, создающих дополнительные условия для совещательных форм политического участия. Такого рода деятельность не обязательно должна приводить к консенсусным решениям. Официальные структуры ЕС постоянно подчёркивают, что их право на принятие окончательных решений не умаляет значимости участия организаций гражданского общества в этом процессе. Таким образом, вклад организаций гражданского общества включает предоставление информации лучшего качест-ва, что в свою очередь стимулирует поиск более обоснованных политических решений.

Некоторые исследователи считают, что включение организаций гражданского общества в разработку политики приобретает особую роль на уровне Евросоюза в силу особенности его управления, которое заключается, прежде всего, в том, что центр, по их мнению, относительно слаб. Они полагают, что, государства-члены стремятся добиться изменений в политике институтов ЕС, которые обладают лишь ограниченной властью в принятии решений, в ус-ловиях постоянно меняющейся институциональной структуры, ограниченной политической легитимности, а зачастую и слабой координаций действий ${ }^{3}$.

Организации гражданского общества играют ещё одну очень важную роль в информационном пространстве, поскольку взаимодействуют с общественной сферой либо в форме медийных кампаний, либо в форме демонстративных акций, тем самым меняя политические подходы и запросы определённых групп населения. Общественные организации связывают политические решения и интересы общества, гарантируя передачу социально значимых вопросов в политическую сферу принятия решений. В этом смысле им принадлежит инновационная роль. Работа таких организаций может быть полезной для государственных социальных служб, помогая им влиять на общественное мнение и донести до широких кругов инфор-мацию о некоторых своих политических решениях, согласованных с субъектами гражданско-го общества.

Взаимодействие в сфере социальных услуг между государствами - членами Европейского союза и социальными движениями гражданского общества крайне важно для институционализации ЕС и для Комиссии, в частности, считает американский политолог профессор Ф. Шмиттер ${ }^{4}$.

Взаимодействие с организациями гражданского общества в информационном пространстве может способствовать достижению более надёжных контактов между сферой социальной поддержки государственного сектора и получателями этой поддержки. Ещё одно очень важное обстоятельство, касающееся деятельности интеграционных объединений. Практика показывает, что общественный сектор может являться каналом и источником

\footnotetext{
${ }^{1}$ Michelmann H. J. Organizational Effectiveness in a Multinational Bureaucracy, Farnborough: Saxon House, 1978.

${ }^{2}$ Jachtenfuchs M. International Policy-Making as a Learning Process? The European Union and the Greenhouse Effect, Aldershot: Avebury, 1996.

${ }^{3}$ Cм., например: Ruzza C. Europe and Civil Society: Movement Coalitions and European Governance, Manchester: Manchester University Press, 2004.

${ }^{4}$ Schmitter P. How to Democratize the European Union and Why Bother? Oxford: Rowman \& Littlefield, 2000.
} Научно-аналитический вестник ИЕ РАН, 2019, №4 
труднодоступной информации, соединяющим национальные и наднациональные институты управления. В этом контексте отношения между группами гражданского общества в государствах-членах и Европейским союзом обеспечивают дополнительный канал для мониторинга и улучшения механизмов управления. По мере того как переход к более широкому использованию структур управления увеличивается и расширяется информационное пространство, возрастает и роль организованного гражданского общества.

Прорыв в информационной сфере в последние десятилетия создал новые благоприятные условия для сотрудничества государственного сектора и гражданского общества. Получение информации от гражданского общества обеспечивает возможность структурам государственной власти принимать оптимальные решения и проводить взвешенную политику с учётом интересов широких слоёв населения.

Прогнозы учёных-футурологов о снижении конфликтов в обществе подтверждается практикой создания механизмов вовлечения общественных организаций и ассоциаций в выработку политических решений в отдельных странах и больших интеграционных объединени-ях стран как, например, Европейский союз. Новыми элементами в жизни общества стали такие явления как общественная сфера связи, сбор информации и её распространение, агрегация предпочтений, совершенствование политики через совещательный процесс, участие в структурах государственной власти и способность представлять общественный сектор получателей государственных услуг на различных территориальных уровнях, транснациональная защита прав человека и др.

Опыт стран Европы показывает, что организациям гражданского общества и каждому человеку в отдельности в условиях формирования нового информационного пространства отводится более значимая роль. Это подтверждается расширением вовлечения организаций гражданского общества в выработку эффективной политики, а также успешной интеграцией общественных организаций различных типов в совместные проекты как между собой, так и с европейским и национальными государственными секторами.

\section{Список литературы}

Иванов Д.В. Виртуализация общества. СПб., изд. «Петербургское Востоковедение», 2000.

Мелюхин И.С. Информационное общество: истоки, проблемы, тенденции развития. М., Издательство МГУ, 1999.

Федотова В.Г. Существуют ли международно-признанные определения информационного общества?. URL: https://iphras.ru/page46589323.htm (дата обращения: 19.07.2019).

\section{References}

Bell D. «The Coming of Post-Industrial Society: A Venture in Social Forecasting Reissue». URL: https:knigogid.ru/books/484415-gryaduschee-postindustrialnoe-obschestvo/toread (дата обращения: 19.07.2019).

Jachtenfuchs M. International Policy-Making as a Learning Process? The European Union and the Greenhouse Effect, Aldershot: Avebury, 1996.

Masuda Y. The Informational Society as Post-Industrial Society. World Future Society. 1981.

Michelmann H. J. Organizational Effectiveness in a Multinational Bureaucracy, Farnborough: Saxon House, 1978.

Rootes C. Environmental Protest in Western Europe, Oxford: Oxford University Press, 2007.

Rootes C. Acting Locally: Local Environmental Mobilizations and Campaigns, London: Научно-аналитический вестник ИЕ РАН, 2019, №4 
Routledge, 2008.

Ruzza C. Europe and Civil Society: Movement Coalitions and European Governance, Manchester: Manchester University Press, 2004.

Schmitter P. How to Democratize the European Union and Why Bother?, Oxford: Rowman \& Littlefield, 2000.

Walker J. L. Mobilizing Interest Groups in America: Patrons, Professions and Social Movements, Ann Arbor: University of Michigan Press, 1991.

\section{Civil society in the modern information space}

Author. Anatoly Kanunnikov, Doctor of Sciences (Politics), Leading Researcher, Center for Social Development of Europe, Department of Social and Political Studies, Institute of Europe, Russian Academy of Sciences. Address: 11-3, Mokhovaya str., Moscow, Russia, 125009. E-mail: a-a-kanunnikov@yandex.ru.

Abstract. Under the conditions of the formation of a new information space, the role of civil society organizations and each individual is growing. Public organizations are becoming an important source of social information. The author concludes that the creation of new information mechanisms for the involvement of public structures in the political decisions making contributes to the reduction of social contradictions and conflicts at the country level and entire integration associations, for example, such as the European Union.

Key words: civil society, information space, information society, development of civilization, non-governmental organizations, political process, European Union.

DOI: http://dx.doi.org/10.15211/vestnikieran420195560 